Brazilian Journal

of Chemical

Engineering

\title{
ENERGY AND EXERGETIC EVALUATION OF THE MULTICOMPONENT SEPARATION OF PETROCHEMICAL NAPHTHA IN FALLING FILM DISTILLATION COLUMNS
}

\author{
Marcelo V. Querino ${ }^{1}$, Ricardo A. F. Machado ${ }^{1}$ and Cintia Marangoni ${ }^{1,2^{*}}$
}

\begin{abstract}
${ }^{1}$ Universidade Federal de Santa Catarina, Campus Florianópolis, Programa de Pós-Graduação em Engenharia Química, Florianópolis, SC, Brasil. ORCID: 0000-0002-9345-5279; ORCID: 0000-0003-1959-1456; E-mail: cintia.marangoni@ufsc.br - ORCID: 0000-0003-2524-6501

${ }^{2}$ Universidade Federal de Santa Catarina, Campus Blumenau, Departamento de Engenharia Têxtil, Blumenau, SC, Brasil.
\end{abstract}

(Submitted: August 10, 2018 ; Revised: February 9, 2019 ; Accepted: February 19, 2019)

\begin{abstract}
Multicomponent separation of synthetic petrochemical naphtha (hexane, cyclohexane, toluene and xylene) was carried out in a falling film distillation sequence with heat supply using a vapor chamber (thermosyphon). Tests were carried out by varying feed flow rate and temperatures of the feed and the vapor chamber in two ways of heat supply: isothermal and with a vapor chamber temperature profile. Regarding the distillation behavior of the multicomponent separation with the proposed falling film column, it was verified that the lower values of the studied variables and the profile temperature mode promoted the best results for hexane recuperation. With an indirect sequence of three columns, hexane mass fraction in the top column increases to the value of 0.82 . Higher thermodynamic efficiency was found for two columns of the sequence in comparison with the conventional ones. This behavior is related to smaller energy consumption, showing a total energy reduction of $12 \%$ compared to the same separation performed in a conventional unit. Energy and exergetic efficiency values were higher than $95 \%$ and $85 \%$ in the three columns used. These analyses demonstrated that the falling film separation proposal is an energy efficient arrangement and could be considered for multicomponent separation. Keywords: Multicomponent distillation; Falling film; Naphtha; Energy efficiency; Exergy.
\end{abstract}

\section{INTRODUCTION}

Distillation processes are modernized in several ways: the most efficient use of available equipment, the adjustment of operating conditions, the replacement of the internal elements of the column, the rearrangement of existing columns in a more complex sequence or the use of side streams. Also, more than one such practice is used at the same time (Olujić et al., 2009; Resetarits et al., 2015). For example, in the case of a single distillation column, Lee and Long (2014) mention that the energy integration is adopted in innumerable ways as in the use of heat pumps, feed splitting, side reboiler or a side condenser, changes in operating pressure, and changing the thermal conditions of the feed stream. Industries that use distillation columns have options of either upgrading units already in operation or using a new advanced column.

The primary purpose of a distillation process is to achieve maximum efficiency at the lowest energy expenditure, and this can be accomplished by modifying the column configuration and/or a sequence of columns (in the case of multicomponent separation). Examples concerning this are the Petlyuk, the Divided Wall Columns (DWC), heat pump distillation, HIDiC (Li et al., 2016) or even these proposals combined (Jana, 2019). Another nonconventional alternative is the use of falling film distillation columns. The main feature of this type of unit is the formation of a thin film of liquid flowing in the longitudinal direction of the inner surface of the distillation duct in an upright position. This process provides an increase in mass

\footnotetext{
* Corresponding author: Cintia Marangoni - E-mail: cintia.marangoni@ufsc.br
} 
and heat transfer, and consequently a reduction in the unit's energy consumption. Kimmel, in 1947, demonstrated that falling film distillation could be an interesting technology since it is an alternative to separate mixtures that require low temperature and the use of high vacuum in conventional units. This technology has been associated with molecular or short path distillation (carried out with vacuum) and more recently to the reduction of energy consumption and tower height (Saifutdinov et al., 2002). Regarding this, Silva Filho et al. (2018), Marangoni et al. (2018) and Marangoni et al. (2019) showed that a falling film device is also practical at atmospheric pressure for mixtures such as aromatics and ethanol/water. Also, the authors established a new configuration for heat supply, which provides energetic advantages in this kind of distillation.

However, even though the use of advanced units is a promising technology, few studies are related to multicomponent separation. Most of the works aim at the optimization of sequential conventional columns to minimize energy requirements, i.e., the thermally coupled distillation system (Shenvi et al., 2013; Saxena et al., 2017); the formulation of a methodology to obtain optimization strategies in the elaboration of several distillation column arrays (Rong and Errico, 2012. Wang et al., 2016) or the comparison of this approach with DWC (Kaibel) columns (Abid et al., 2018). None of these studies present the use of a falling film as an approach to minimize energy requirements for multicomponent separation. Besides, most of them consist of simulated studies, being scarce the presentation of experimental data.

The falling liquid film has become one of the most effective ways of transferring heat and mass in the processes of evaporation and condensation (Abraham and Mani, 2015). However, as with the other nonconventional distillations cited, since it uses a different form for heat supply, it is necessary to provide more valuable information concerning the energetic analysis. In this sense, the concept of exergy establishes a universal standard for the use of energy where the exergetic losses (irreversibility rate) consist of a measure of degradation of the quality of energy (Araujo et al., 2007). This concept can be used as a methodology to define hybrid distillation structures for ethanol refining, as demonstrated by Suleiman et al. (2014). Also, it can be used to show that thermal integration among columns promotes energy savings (Dias et al., 2011).

In this work, the energy integration in the separation of multicomponent mixtures was experimentally studied in a falling film distillation column with heat supply using a vapor chamber (thermosyphon). The heat supply is carried out by a non-condensable gas vapor chamber based on phase change heat transfer, requiring lower thermal gradients and reducing the thermal resistance to heat transfer and thereby allowing the minimization of the requirements of energy in a distillation unit (Michels et al., 2012). Thus, combining the complexity of the experimental study of multicomponent mixtures with the search for energy minimization as well as the intensification of processes, the general objective of this work was to investigate the multicomponent separation of a mixture of synthetic naphtha in a distillation sequence of film columns assisted by a thermosyphon operating at atmospheric pressure.

\section{MATERIALS AND METHODS}

\section{Description of the experimental unit}

The experiments were carried out in a falling film distillation unit as shown in Figure 1 (a). The operation was carried out in a continuous mode, where the feed was placed in the main tank, whose objective was homogenization between the bottom and top products obtained in the separation and hence producing continuously the feed. A centrifugal pump maintained the tank under agitation. The feed stream was pumped into a plate heat exchanger and in the sequence enters at the top of the distillation tube. In this tube, the mass and heat transfer occur, and part of the distilled fluid was collected as the top product in the accumulator tank; the bottom product was redirected to the mixing tank where it, in turn, mixes the two streams. Around the distillation tube, concentrically, there was the condenser section of the biphasic thermosyphon (vapor chamber), which supplies heat integrally along the distillation tube. The thermosyphon could heat the unit in isothermal mode or temperature profile mode as the presence of non-condensable gases inside the condensation section of the thermosyphon increases. Figure 1 (b) shows the representation of this geometry and the position of the thermocouples allocated along the outside of the vapor chamber. More details of the experimental unit are presented in Silva Filho et al. (2018)
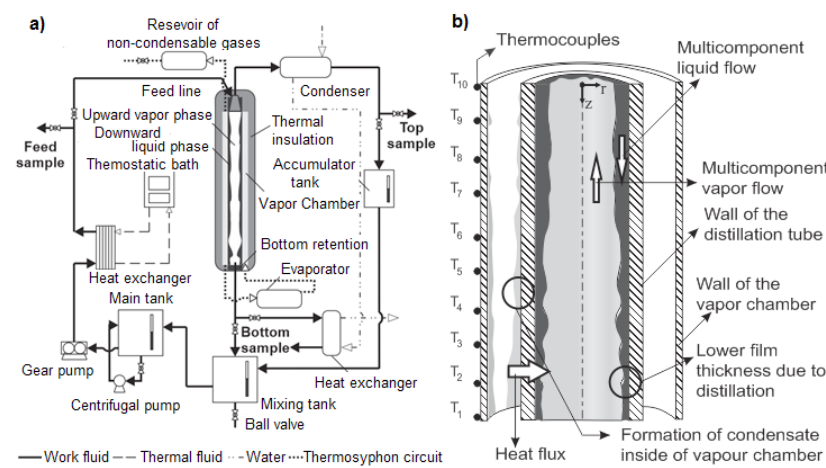

Figure 1. Schematic diagram of the falling film distillation unit (a), and representation of the vapor chamber (b). 


\section{Experimental Tests}

A fraction of synthetic naphtha was prepared to represent the multicomponent mixture. Four compounds were used: n-hexane and its isomers, cyclohexane, toluene and xylene isomers. The separation was carried out in a three-column sequence. In the first one, the behavior of the process was evaluated by studying the influence of three variables: feed flow rate, $Q_{f}$, feed temperature, $T_{f}$, and temperature of the vapor chamber at $T_{1}$. Also, two modes of operation were used in the vapor chamber: isothermal and profile. In the latter, a temperature profile along the vapor chamber was established, generating a gradient of $10 \mathrm{~K}$ between the thermocouples $\mathrm{T}_{1}$ and $\mathrm{T}_{10}$. The experiments were carried out on a steady state; the experimental conditions tested in the first column of the distillation sequence were: feed flow rate, $Q_{f}(22$ - $\left.12 \mathrm{~kg} \cdot \mathrm{h}^{-1}\right)$, feed temperature, $\mathrm{T}_{\mathrm{f}}(358-363 \mathrm{~K})$ and temperature of the vapor chamber, $\mathrm{T}_{1},(363-368 \mathrm{~K})$. Table 1 presents the sequence of experiments carried out in the first column.

The composition of the feed stream at the first column of the sequence was: 0.23 of $n$-hexane and its isomers, 0.25 of cyclohexane, 0.25 of toluene and 0.26 of xylenes (mass fractions); mixture here cited as synthetic naphtha. For the other columns of the sequence, the feed stream consisted of the same as obtained at the top stream of the previous column (same composition). In this way, a sequence of three columns in indirect form was used to promote the separation of the defined light key component: n-hexane.

Samples were collected from the top and bottom streams of the column in triplicate and duplicate analyses were performed. The ASTM D6526-12 gas chromatography method was used for the analysis of the separated chemical compounds in the experimental distillation. A Shimadzu GC-2010 gas chromatograph was used, containing an Agilent Technologies brand CP4423 chromatographic column coupled to an AOC5000 sample injection system.

From the mean values of the mass fractions, the separation factor was determined. The separation factor (SF) is the relation between the ratio of the mass

Table 1. Experimental conditions used in the first column of the distillation sequence.

\begin{tabular}{|c|c|c|c|c|}
\hline \multicolumn{2}{|c|}{$\begin{array}{l}\text { Number of } \\
\text { experiment }\end{array}$} & \multirow{2}{*}{$\begin{array}{c}Q_{\mathrm{f}} \\
\left(\mathrm{kg} \cdot \mathrm{h}^{-1}\right)\end{array}$} & $\mathbf{T}_{\mathrm{f}}$ & $\mathbf{T}_{\mathbf{1}}$ \\
\hline Isothermal & Profile & & \multicolumn{2}{|c|}{ (K) } \\
\hline 1 & 9 & $22(1)$ & $358(-1)$ & $363(-1)$ \\
\hline 2 & 10 & $22(1)$ & $358(-1)$ & $368(1)$ \\
\hline 3 & 11 & $22(1)$ & 363 (1) & $368(1)$ \\
\hline 4 & 12 & $22(1)$ & 363 (1) & $363(-1)$ \\
\hline 5 & 13 & $12(-1)$ & 363 (1) & $363(-1)$ \\
\hline 6 & 14 & $12(-1)$ & 363 (1) & $368(1)$ \\
\hline 7 & 15 & $12(-1)$ & $358(-1)$ & $368(1)$ \\
\hline 8 & 16 & $12(-1)$ & $358(-1)$ & $363(-1)$ \\
\hline
\end{tabular}

fractions of the light and heavy key components in the top and bottom streams, and is defined according to Equation 1:

$$
\mathrm{SF}=\frac{\mathrm{w}_{\text {hex }, \mathrm{t}} / \mathrm{w}_{\mathrm{xy}, \mathrm{t}}}{\mathrm{w}_{\text {hex }, \mathrm{b}} / \mathrm{w}_{\mathrm{xyl}, \mathrm{b}}}
$$

The Tukey test was applied for two responses of the first column of the distillation sequence: the hexane mass fraction and separation factor. The p-value was compared to a $5 \%$ significance level to assess the null hypothesis (that states that the population means are all equal) to determine whether any of the differences between the means are statistically significant. Results for both responses analyzed demonstrated that there are experiments with significantly different performance. Then, the Tukey test was applied to identify which operational conditions differ among each other. The objective was to evaluate which mode of operation allows better separation: isothermal (experiments 1 to 8 ) or with a temperature profile (experiments 9 to 16), and then apply this condition for the other columns of the sequence.

Energetic and exergetic efficiency values of the distillation tube were defined as the ratio of the outlet to the inlet. Therefore, the energies were associated with the top and bottom streams, and the energies that enter the distillation tube (the energy associated with the feed stream and the energy supplied by the vapor chamber). Inlet variables were the composition of the feed, top and bottom streams; temperatures; mass flow and component mass fractions. For the energetic and exergetic balances, evaporator power and column pressure were also used. A global mass balance and a component balance (Equation 2) were done, followed by an energy balance (Equation 3), an entropy balance (Equation 4) and finally, the exergy balance (Equation 5). The control volume defined (cv) was the distillation tube. The control volume temperature, $T_{c v}$. is the arithmetic mean of the $T_{1}$ to $T_{10}$ thermocouples (reference temperature $=298 \mathrm{~K}$ ). The exergy balance equations used in this work are those provided by Bejan (2016). There is no work in the process; therefore, $\mathrm{W}$ is null. Q refers to the evaporator power (vapor chamber) and, for this case, it was assumed that there are no losses to the environment because the vapor chamber is around the distillation tube.

$$
\begin{aligned}
& \frac{\mathrm{dm}_{\mathrm{cv}}}{\mathrm{dt}}=\sum_{\text {in }} \dot{\mathrm{m}}-\sum_{\text {out }} \dot{\mathrm{m}} \\
& \frac{\mathrm{dE}_{\mathrm{cv}}}{\mathrm{dt}}=\mathrm{Q}_{\mathrm{cv}}-\mathrm{W}_{\mathrm{cv}}+\sum_{\text {in }}(\dot{\mathrm{m}} \cdot \mathrm{H})-\sum_{\text {out }}(\dot{\mathrm{m}} \cdot \mathrm{H})
\end{aligned}
$$


$\frac{\mathrm{dS}_{\mathrm{cv}}}{\mathrm{dt}}=\sum_{\text {in }}(\dot{\mathrm{S}})-\sum_{\text {out }}(\dot{\mathrm{S}})+\sum_{\mathrm{cv}}\left(\frac{\mathrm{Q}_{\mathrm{cv}}}{\mathrm{T}_{\mathrm{cv}}}\right)+\dot{\mathrm{S}}_{\mathrm{ge}}$

$\frac{\mathrm{d} \varepsilon}{\mathrm{dt}}=\sum_{\text {in }}(\dot{\varepsilon})-\sum_{\text {out }}(\dot{\varepsilon})+\sum_{\text {in }}\left(1-\frac{\mathrm{T}_{0}}{\mathrm{~T}_{\mathrm{cv}}}\right) \mathrm{Q}_{\mathrm{cv}}-\mathrm{W}_{\mathrm{cv}}-\mathrm{I}_{\mathrm{cv}}$

Simulations were carried out using the Honeywell's UniSim ${ }^{\circledR}$ process modeling software to represent each one of the experiments. For these, enthalpy, entropy and physical exergy were obtained. Only thermal exergy was considered, composed of the physical and chemical exergy. Standard values for molar exergy were obtained from Bejan (2016): 4106, 3901, 3939 and $4591 \mathrm{~kJ} \cdot \mathrm{mol}^{-1}$ for hexane, cyclohexane, toluene and xylene, respectively; and were used to calculate the chemical exergy of the streams (Equation 6). Physical exergy was calculated according to Equation 7.

$\varepsilon_{\mathrm{q}}=\sum\left(\mathrm{x}_{\mathrm{i}} \cdot \varepsilon_{\mathrm{q}, \mathrm{i}}\right)+\mathrm{R} \cdot \mathrm{T}_{0} \sum\left(\mathrm{x}_{\mathrm{si}} \cdot \ln \mathrm{x}_{\mathrm{i}}\right)$

$\varepsilon_{\mathrm{f}}=\Delta \mathrm{H}-\mathrm{T}_{0} \cdot \Delta \mathrm{S}$

Based on the previous balance equations, efficiencies were calculated by Equation 8 for the energy $(\xi)$ and Equation 9 for the exergy $(\psi)$.

$\xi=\frac{E_{\text {out }}}{E_{\text {in }}}$

$\psi=\frac{\varepsilon_{\text {out }}}{\varepsilon_{\text {in }}}$

Thermodynamic efficiency was calculated according to Equation 10, as described by Demirel (2004), where $\omega_{\min }$ represents the minimum work required for a reversible separation (Equation 11) and L $\omega$ the lost work (Equation 12).

$\eta=\frac{\omega_{\min }}{\mathrm{L} \omega+\omega_{\min }}$

$\omega_{\min }=\sum_{\text {out }} \dot{\mathrm{m}}\left(\mathrm{H}-\mathrm{T}_{0} \cdot \mathrm{S}\right)-\sum_{\text {in }} \dot{\mathrm{m}}\left(\mathrm{H}-\mathrm{T}_{0} \cdot \mathrm{S}\right)$

$\mathrm{L}=\sum_{\text {in }} \dot{\mathrm{m}}\left(\mathrm{H}-\mathrm{T}_{0} \cdot \mathrm{S}\right)-\sum_{\text {out }} \dot{\mathrm{m}}\left(\mathrm{H}-\mathrm{T}_{0} \cdot \mathrm{S}\right)+\sum_{\text {in }}\left(1-\frac{\mathrm{T}_{0}}{\mathrm{~T}_{\mathrm{r}}}\right) \mathrm{Q}_{\mathrm{r}}$

\section{RESULTS AND DISCUSSION}

The influence of the tested variables on the hexane mass fraction in the top stream was studied aiming to evaluate the behavior of the falling film unit for multicomponent separations, (Figure 2). For the tests carried out in the isothermal mode, feed flow rate $\left(Q_{f}\right)$ has less influence in the increment of the mass fraction of hexane and $T_{1}$ has the most influence. For the temperature profile, $\mathrm{T}_{\mathrm{f}}$ is the most relevant variable. In both cases, the results demonstrated that the lower values of the variables tested provided the most substantial increases in the mass fraction, thus indicating the behavior of the falling film unit in the separation of multicomponent mixtures. These results have similarities with the previous works of the research group with different mixtures (Silva Filho et al., 2018; Marangoni et al., 2018; Marangoni et al., 2019). However, when the multicomponent and the binary systems previously studied are compared, it can be observed that each mixture has different optimal conditions (qualitatively), thus indicating that hydrodynamic aspects influenced by the mixture properties (such as viscosity) determine the performance of the process.

It is important to note that separation on the falling film distillation column with the multicomponent hydrocarbon mixture was observed even though a
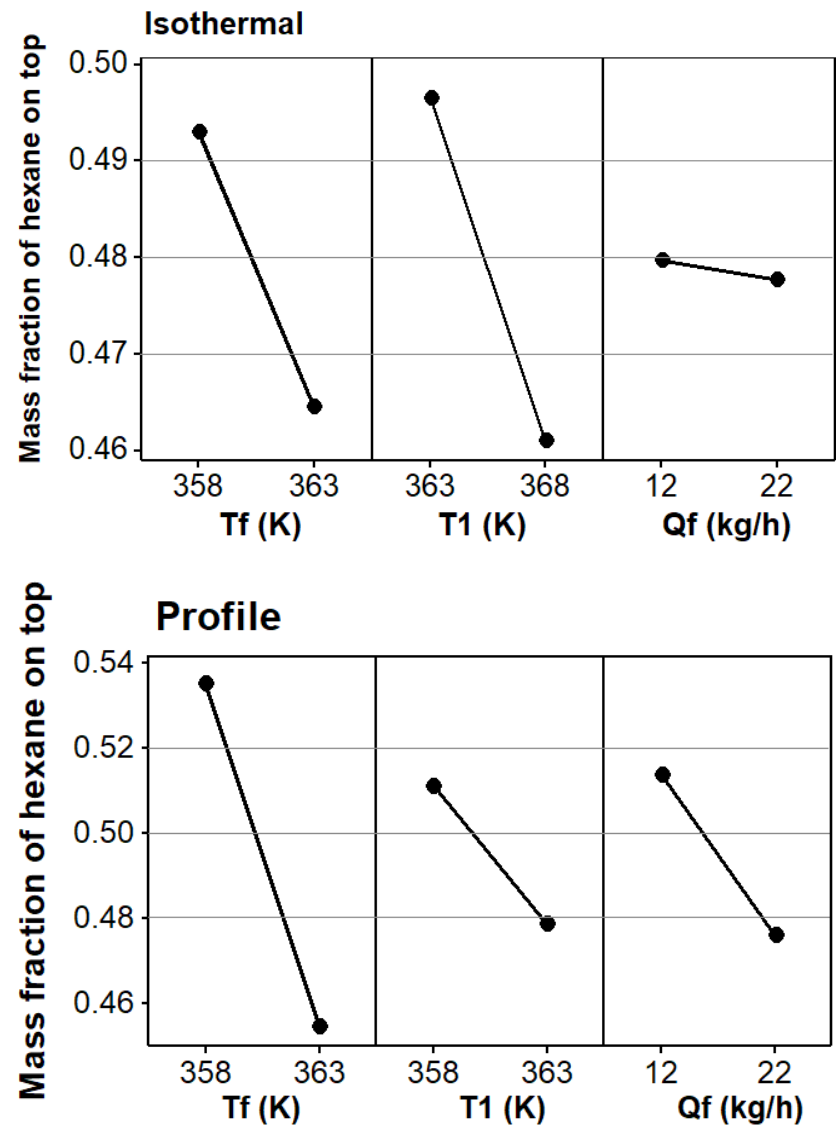

Figure 2. Influence of the variables evaluated on the mass fraction of hexane in the top stream for the experiments carried out in the first column of the distillation sequence. 
high degree of purity was not obtained for the hexane in the first column. That is, with the proposed unit it was possible to enrich the mass fraction of the key component (hexane) in both heat supply modes, either isothermal or with a temperature profile in the vapor chamber. This result indicates the potential for the use of this type of unit for the separation of multicomponent mixtures.

Table 2 shows the results of the hexane mass fraction at the top stream $\left(\mathrm{w}_{\text {hex, }}\right)$, as well as the separation factor (SF); both obtained in the experiments with the first column of the distillation sequence operating with isothermal mode (experiments 1 to 8 ) and with a temperature profile (9 to 16). As expected, tests with higher separation factor values showed the highest hexane mass fractions at the top ( 1 and 8 in isothermal mode, $9,10,15$ and 16 in profile mode). It is desired that the value of the separation factor be as large as possible, a fact which indicates greater ease in the separation. Thus, experiment 16 was considered to be the best among all tested because it presented the greatest hexane fraction and separation factor. This experiment was performed in a temperature profile mode in the vapor chamber; the feed flow rate was $12 \mathrm{~kg} \cdot \mathrm{h}^{-1}$, the feed temperature was $358 \mathrm{~K}$, and the temperature $\mathrm{T}_{1}$ was $363 \mathrm{~K}$.

Although the analysis of the hexane mass fraction and separation factor indicated that the experimental conditions of experiment 16 are the best for the first column of the sequence, the Tukey test was applied to the hexane mass fraction and to the separation factor to determine which experiment was statistically different from the others. Table 2 also shows the results of the Tukey test. The letters indicate statistically equal means of the experimental results by the test at $5 \%$ of significance, i.e., similar letters in the experiment

Table 2. Results of the separation factor, the mass fraction of hexane at the top and the Tukey test for the experiments carried out in isothermal and temperature profile mode.

\begin{tabular}{cll}
\hline Experiment & \multicolumn{1}{c}{$\mathbf{S F}^{*}$} & \multicolumn{1}{c}{$\mathbf{W}_{\text {hex }, \mathbf{t}^{*}}$} \\
\hline 1 & $13.70 \pm 0.88^{\text {adegklmn }}$ & $0.49 \pm 0.00^{\text {ahmn }}$ \\
2 & $8.78 \pm 0.55^{\text {bcdegklmn }}$ & $0.45 \pm 0.01^{\text {bdefgklmn }}$ \\
3 & $8.21 \pm 0.49^{\text {bcdefgklmn }}$ & $0.43 \pm 0.00^{\text {bcdefgkl }}$ \\
4 & $9.37 \pm 0.75^{\text {abcdefgklmn }}$ & $0.45 \pm 0.01^{\text {bcdefgklmn }}$ \\
5 & $10.80 \pm 0.89^{\text {abcdefgklmn }}$ & $0.46 \pm 0.01^{\text {bcdefgklmn }}$ \\
6 & $8.52 \pm 0.74^{\text {bcdefgklmn }}$ & $0.43 \pm 0.00^{\text {bcdefgkl }}$ \\
7 & $9.53 \pm 0.69^{\text {abcdefgklmn }}$ & $0.45 \pm 0.01^{\text {bcdefgklmn }}$ \\
8 & $17.70 \pm 2.02^{\text {hjo }}$ & $0.50 \pm 0.01^{\text {abjno }}$ \\
9 & $26.60 \pm 2.90$ & $0.53 \pm 0.01^{\text {hino }}$ \\
10 & $16.80 \pm 2.81^{\text {hj }}$ & $0.50 \pm 0.01^{\text {abjm }}$ \\
11 & $9.31 \pm 0.72^{\text {abcdefgklmn }}$ & $0.45 \pm 0.01^{\text {bcedfgklmn }}$ \\
12 & $10.00 \pm 0.48^{\text {abcdefgklmn }}$ & $0.46 \pm 0.00^{\text {bcdefgklmn }}$ \\
13 & $11.90 \pm 0.70^{\text {abcdefgklmn }}$ & $0.47 \pm 0.01^{\text {bbdegjklmn }}$ \\
14 & $10.80 \pm 0.74^{\text {abcdefgklmn }}$ & $0.46 \pm 0.01^{\text {bcdegklmn }}$ \\
15 & $21.70 \pm 0.84^{\text {ho }}$ & $0.53 \pm 0.00^{\text {hio }}$ \\
16 & $36.70 \pm 4.36$ & $0.58 \pm 0.04$ \\
\hline
\end{tabular}

*Values are expressed as mean and standard deviation of 6 measurements. indicate that they do not differ statistically from each other. For example, the mean of the separation factor of experiment 1 is higher than that if 2 (indicated by the presence of the letter a); but this experiment does not have a statistical difference from experiment 4 (as this also presents the letter a). When the separation factor is analyzed, two experiments demonstrated differences: 9 and 16. In fact, these presented the major separation factor and were carried out in isothermal and temperature profile mode. However, when the hexane mass fraction at the top of the column is analyzed, only experiment 16 showed a statistical difference. As both responses are considered essential to define the best conditions for column 1, experiment 16 was confirmed as the best one by the Tukey test since there is no similarity with any other experiment (indicated by the absence no presence of the letters).

To evaluate if the proposal was also energy advantageous for a multicomponent separation, a simulation was done using a process simulator for a single column reproducing the same separation of the falling film in a conventional column. So, a conventional unit with the same conditions and separation results as those obtained with the falling film unit in experiment 16 was designed (shortcut and latter rigorous method). Table 3 summarizes the results that compare both approaches. It was observed that the energy required for the separation in the falling film column (represented by the power results) showed a reduction of at least $20 \%$ compared to a conventional unit, encouraging the research on energy assessment following multicomponent separation units.

The experiments carried out with the column sequence were done on three sequential units arranged in an indirect series, in order to obtain separation of the hexane from the other components. Thus, in the second column, the feed stream composition corresponded to the composition obtained in the top stream of the best condition of the first column (experiment 16). In this second column, these conditions were used: feed flow rate of $12 \mathrm{~kg} \cdot \mathrm{h}^{-1}$, feed temperature of $343 \mathrm{~K}$ and temperature of the vapor chamber of $\mathrm{T}_{1} 360 \mathrm{~K}$. The experiments were conducted in the temperature profile mode, and the fraction of hexane in the top stream obtained was incremented to 0.72 .

Table 3. Comparison of results between the falling film unit (higher separation obtained - experiment 16) and a conventional unit (simulated reproducing the same separation as experimentally obtained).

\begin{tabular}{lcc}
\hline & Falling film & Conventional \\
\hline $\mathrm{Q}_{\mathrm{t}}\left(\mathrm{kg} \cdot \mathrm{h}^{-1}\right)$ & 0.08 & 0.08 \\
$\mathrm{X}_{\text {hex }, \mathrm{t}}$ & 0.59 & 0.58 \\
$\mathrm{X}_{\mathrm{cyc}, \mathrm{t}}$ & 0.32 & 0.31 \\
$\mathrm{X}_{\text {tol, }}$ & 0.07 & 0.09 \\
$\mathrm{X}_{x i l, \mathrm{t}}$ & 0.02 & 0.02 \\
Pow $(\mathrm{W})$ & 137 & 172 \\
\hline
\end{tabular}


From the composition of this stream, the separation was carried out in the third column. The feed flow rate used was $12 \mathrm{~kg} \cdot \mathrm{h}^{-1}$; the feed temperature was $340 \mathrm{~K}$ and the temperature of the vapor chamber - $\mathrm{T}_{1}$ - was $345 \mathrm{~K}$. In this last column, the hexane mass fraction in the top stream was increased to 0.82 . It is noteworthy that, in both the second and third units, variations in the temperatures employed were evaluated in order to obtain the highest enrichment of hexane in the top stream, based on the knowledge of the separation behavior previously reported. However, aiming at the study of energy integration, these results are not presented since they only corroborate the behavior already studied.

The results of the experiments were compared for each unit of the indirect distillation sequence with the simulations representative of the same separation (procedure previously mentioned). Table 4 summarizes the results of power and thermodynamic efficiency obtained. The energy savings provided by the indirect distillation sequence in the falling film column was $74.3 \mathrm{~W}$ compared to a conventional unit, or $12 \%$. It is well known that thermally coupled multiple effect distillation columns promote $20-40 \%$ of energy savings in multicomponent separations compared to the conventional structures (Halvorsen and Skogestad, 2011). Results demonstrated that the proposal of falling film distillation is also a promising alternative for nonconventional columns with energy savings because this parameter showed a similar value.

As cited by Demirel (2004), the thermodynamic efficiency of distillation systems is generally low; results presented here concerning this variable are in agreement with this. However, an interesting fact is that the thermodynamic efficiency values of the falling film column were higher than the conventional column for columns 1 and 3 - when reduced values were obtained in the evaporator consumption. These results indicate that falling film distillation presented a decrease of the thermodynamic imperfections, better heat distribution, less energy required, and this innovative system is advantageous when compared to a conventional unit.

It was found that the lower the difference between the bubble temperature and the temperature used in the feed stream, the higher the energy savings. For the experiments carried out on the falling film columns 1,2 and 3 the temperature differences were 278.62
$\mathrm{K}, 286.23 \mathrm{~K}$, and $278.03 \mathrm{~K}$, respectively. The third column of the indirect distillation sequence showed the most substantial decrease in the energy consumption of the evaporator, approximately $42 \%$. In this unit, the top temperature was $333 \mathrm{~K}$, which is lower than the boiling temperature of $n$-hexane $(341 \mathrm{~K})$. In this steady state, the falling film distillation unit remained stabilized and allowed the greater enrichment of the hexane mass fraction at the top stream. The film column was stabilized at a temperature below the boiling temperature of $n$-hexane. That is, the multiplicity of stationary states was demonstrated, as reported by Luyben (2010).

Figure 3 shows the results obtained for the determination of energy and exergetic efficiencies for all the experiments with the falling film distillation. Also, the power values supplied to the evaporator of the vapor chamber were presented. The markers in bold refer to the best experiment of each column in the distillation sequence, and these detailed results are summarized in Tables 5 and 6 .

Experiments with higher power values $(17,18$, 19, 20 and 29) apparently led to a decrease in the two efficiencies. The efficiency values of the other experiments were higher than $85 \%$, and experiments carried out with the isothermal mode (experiments 1 to 8) presented energy efficiency values higher than those with the temperature profile. This behavior is associated with higher irreversibility, consequently higher entropy resulted in these experiments. In fact, these are the tests with high values for the top flow rate

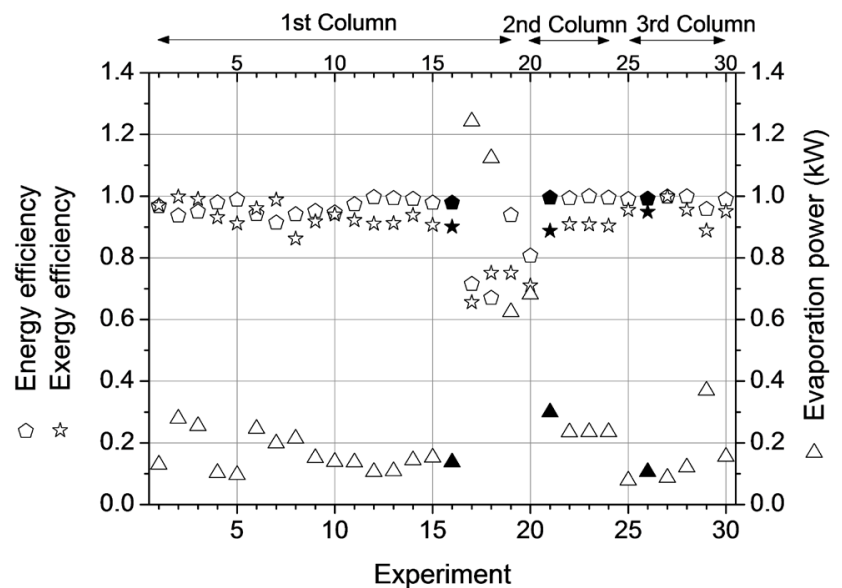

Figure 3. Energetic and exergetic efficiencies of the synthetic naphtha separation on a falling film column.

Table 4. Energy and thermodynamic efficiency for separation carried out on the falling film unit and on conventional columns simulated to represent the same separation.

\begin{tabular}{ccccc}
\hline Falling film & Pow $(\mathbf{W}) *$ & $\boldsymbol{\eta}$ & Conventional & Pow (W)* \\
\hline Column 1 & 137.0 & 0.17 & Column 1 & 172.5 \\
Column 2 & 299.0 & 0.25 & Column 2 & 220.5 \\
Column 3 & 105.5 & 0.28 & Column 3 & 0.11 \\
\cline { 2 - 5 } & 541.5 & & & 0.11 \\
\hline
\end{tabular}

*Power supplied to the evaporator (falling film) or the reboiler (conventional). 
and lower separation, which led to lower energy and exergy efficiency values.

In most experiments, the exergetic efficiency was lower than the energy one. This result is corroborated by other studies in the literature (Al-Muslim; Dincer, 2005; Piacentino, 2015). But, in the present study, the exergy values obtained in the experiments in the falling film column were higher than those reported, and this could be explained by the fact that only the distillation tube was used in the analysis (control volume).

Physical and chemical exergy values are similar in the material streams of all three columns used, but it is important to note that column 3 has the higher energetic efficiency and chemical exergy. The chemical exergy concept is associated with the mass and heat transfer; so, the higher values of these variables are explained by the heat transfer through all the vapor chamber (thermosyphon) and the distillation tube.

The total input energy in each column of the sequence includes energy associated with material feed as well as the thermal energy input. The higher values observed for energetic efficiency demonstrated that as proposed heat supply by a thermosyphon led to the lowest energy requirements.

Table 5. Energy, entropy and exergy results of the inlet and outlet material streams for the best experiments of each column used in the sequence.

\begin{tabular}{lccc}
\hline \multicolumn{1}{c}{ Variable } & Feed & Top & Bottom \\
\hline & Column 1 & & \\
Enthalpy $\left(\mathrm{kJ} \cdot \mathrm{kg}^{-1}\right)$ & -890.98 & -1848.82 & -865.70 \\
Entropy $\left(\mathrm{kJ} \cdot \mathrm{kg}^{-1} \cdot{ }^{\circ} \mathrm{C}^{-1}\right)$ & -0.26 & 0.08 & -0.24 \\
Physical exergy $\left(\mathrm{kJ} \cdot \mathrm{kg}^{-1}\right)$ & 10.44 & 6.79 & 10.85 \\
Chemical exergy $\left(\mathrm{kJ} \cdot \mathrm{kg}^{-1}\right)$ & 46.49 & 72.72 & 45.65 \\
\hline \multicolumn{4}{c}{ Column 2} \\
Enthalpy $\left(\mathrm{kJ} \cdot \mathrm{kg}^{-1}\right)$ & -1791.24 & -1996.95 & -1764.28 \\
Entropy $\left(\mathrm{kJ} \cdot \mathrm{kg}^{-1} \cdot{ }^{\circ} \mathrm{C}^{-1}\right)$ & 0.03 & 0.41 & 0.08 \\
Physical exergy $\left(\mathrm{kJ}^{-1} \mathrm{~kg}^{-1}\right)$ & 4.39 & 5.99 & 7.14 \\
Chemical exergy $\left(\mathrm{kJ} \cdot \mathrm{kg}^{-1}\right)$ & 69.96 & 79.06 & 69.80 \\
\hline \multicolumn{4}{c}{ Column 3 } \\
Enthalpy $\left(\mathrm{kJ} \cdot \mathrm{kg}^{-1}\right)$ & -1993.39 & -2099.81 & -1971.63 \\
Entropy $\left(\mathrm{kJ} \cdot \mathrm{kg}^{-1} \cdot{ }^{\circ} \mathrm{C}^{-1}\right)$ & 0.44 & 0.64 & 0.40 \\
Physical exergy $\left(\mathrm{kJ} \cdot \mathrm{kg}^{-1}\right)$ & 5.80 & 4.39 & 6.16 \\
Chemical exergy $\left(\mathrm{kJ} \cdot \mathrm{kg}^{-1}\right)$ & 78.77 & 84.64 & 77,68 \\
\hline
\end{tabular}

For the three falling film columns used in the sequence proposed, the results showed that the higher the aggregate exergetic efficiency across the units the smaller the lost work (irreversibility). The higher values of exergetic efficiency indicate the good capability of separation of these columns with minimum work.

\section{CONCLUSION}

The two operational modes of heat supply to the vapor chamber, isothermal and temperature profile, allow the enrichment of the hexane mass fraction in the top stream, demonstrating the possibility of using a falling film unit for the separation of multicomponent mixtures. The Tukey test showed that the temperature profile mode is more advantageous for this separation.

Reduced total energy consumption is a priority for the chemical and petrochemical industries were distillation is an energy intensive process. The multicomponent separation using a falling film distillation sequence showed a $12 \%$ reduction in power consumption when compared to conventional simulations. This result indicates the potential of the use of thermosyphon-assisted falling film units as both a single unit (where a $20 \%$ reduction in energy consumption was observed) and in a distillation sequence.

Furthermore, the values of the energy and exergetic efficiencies are higher than $95 \%$ and $85 \%$, respectively, showing that this is an energy efficient arrangement and could be considered for multicomponent separation.

\section{NOMENCLATURE}

$\begin{array}{ll}\mathrm{E} & \text { Energy }(\mathrm{J}) \\ \mathrm{H} & \text { Enthalpy }(\mathrm{J}) \\ \mathrm{I} & \text { Irreversibility of the process }(\mathrm{J}) \\ \mathrm{m} & \text { Mass }(\mathrm{kg}) \\ \mathrm{m} & \text { Mass flow }\left(\mathrm{kg} \cdot \mathrm{s}^{-1}\right) \\ \text { Pow } & \text { Power supplied to the evaporator }(\mathrm{W}) \\ \mathrm{Q} & \text { Heat }(\mathrm{J}) \\ \mathrm{Q}_{\mathrm{f}} & \text { Feed flow rate }\left(\mathrm{kg} \cdot \mathrm{h}^{-1}\right)\end{array}$

Table 6. Results concerning energy and exergy balances and efficiencies of the best experiments of each column used in the sequence.

\begin{tabular}{|c|c|c|c|c|c|c|c|}
\hline & \multicolumn{3}{|c|}{ Energy balance } & \multicolumn{4}{|c|}{ Exergy balance } \\
\hline & C1 & $\mathrm{C} 2$ & C3 & & $\mathrm{C} 1$ & C2 & C3 \\
\hline$\sum_{\text {in }} \dot{m} \cdot H$ & -3.368 & -6.134 & -6.651 & $\sum_{\text {in }} \dot{\varepsilon}$ & 0.215 & 0.255 & 0.255 \\
\hline$\sum_{\text {out }} \dot{\mathrm{m}} \cdot \mathrm{H}$ & -3.294 & -6.104 & -6.593 & $\sum_{\text {out }} \dot{\varepsilon}$ & 0.214 & 0.266 & 0.266 \\
\hline $\mathrm{Q}_{\mathrm{cv}}$ & 0.137 & 0.298 & 0.298 & $\sum\left(1-\frac{\mathrm{T}_{0}}{\mathrm{~T}_{\mathrm{cv}}}\right) \mathrm{Q}_{\mathrm{cv}}$ & 0.022 & 0.044 & 0.044 \\
\hline$\xi$ & 0.93 & 0.94 & 0.97 & $\begin{array}{l}\mathrm{I}_{\mathrm{cV}} \\
\psi\end{array}$ & $\begin{array}{c}0.023 \\
0.90\end{array}$ & $\begin{array}{c}0.033 \\
0.88\end{array}$ & $\begin{array}{c}0.033 \\
0.88\end{array}$ \\
\hline
\end{tabular}

C refers to the column; all terms of the balance are expressed in $\mathrm{kJ} . \mathrm{s}^{-1}$. 


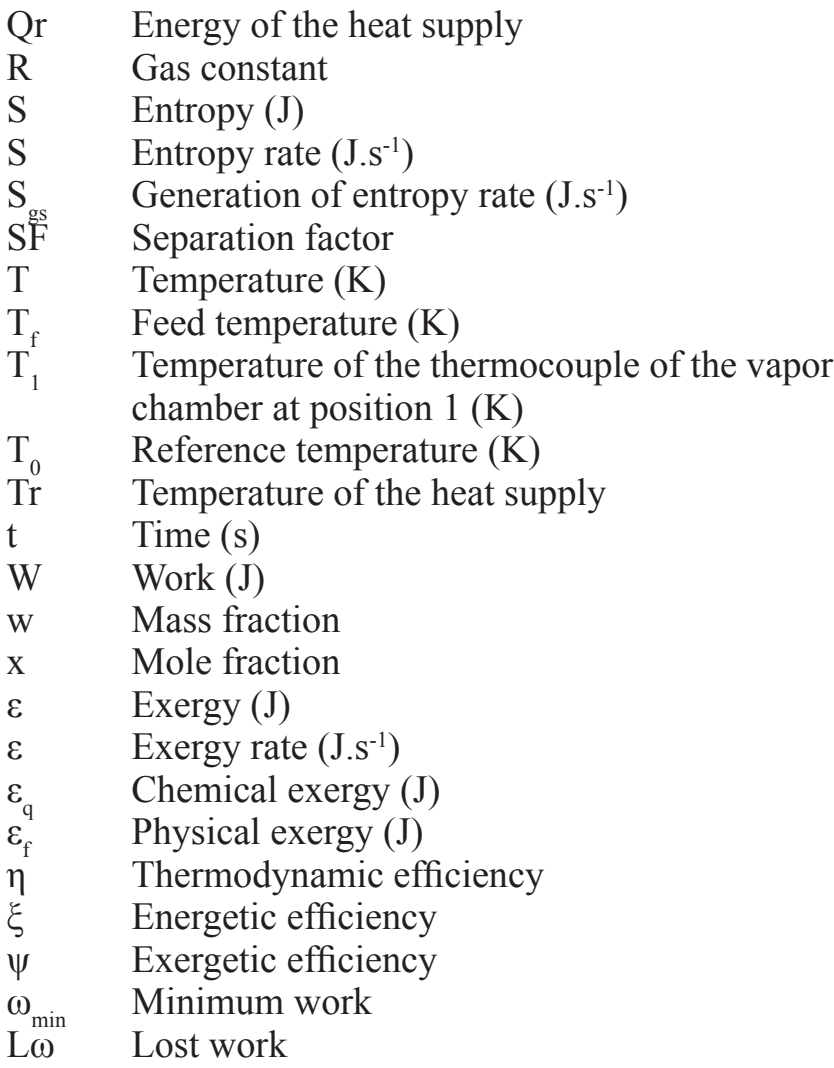

$\begin{array}{ll}\text { Subscripts } \\ \text { b } & \text { Bottom stream } \\ \text { cyc } & \text { Cyclohexane } \\ \text { hex } & \text { Hexane } \\ \text { i } & \text { Component } \\ \text { t } & \text { Top stream } \\ \text { tol } & \text { Toluene } \\ \text { xyl } & \text { Xylene }\end{array}$

\section{ACKNOWLEDGMENTS}

The authors thank the National Petroleum, Natural Gas and Biofuels Agency (ANP) for the support provided in the form of the Human Resources Program PRH 34 ANP / MCT. This study was financed in part by the Coordenação de Aperfeiçoamento de Pessoal de Nível Superior - Brasil (CAPES) - Finance Code 001. The authors are grateful for the academic UniSim ${ }^{\circledR}$ license given by Honeywell.

\section{REFERENCES}

Abraham, R., Mani, A. Heat transfer characteristics in horizontal tube bundles for falling film evaporation in multi-effect desalination system. Desalination, 375, 129-137 (2015). https://doi.org/10.1016/j. desal.2015.06.018

Abid, F., Shamsuzzoha, M., Binous, H., Alshammari, A. Optimal operation and control of four-product dividing-wall (Kaibel) distillation column. Arabian
Journal for Science and Engineering, 43, 6067-6085 (2018). https://doi.org/10.1007/s13369-018-3259-2

Al-Muslim, H., Dincer, I. Thermodynamic analysis of crude oil distillation systems. International Journal of Energy Research, 29, 637-655 (2005). https:// doi.org/10.1002/er.1097

Araújo, A.B., Brito, R.P., Vasconcelos, L.S. Exergetic analysis of a distillation processes - A case study. Energy, 32, 1185-1193 (2007). https://doi. org/10.1016/j.energy.2006.07.003

Bejan, A. Advanced Engineering Thermodynamics. John Wiley \& Sons, New Jersey (2016). https://doi. org/10.1002/9781119245964

Demirel, Y. Thermodynamics analysis of separation systems. Separations Science and Technology, 39, 3897-3942 (2004). https://doi.org/10.1081/SS200041152

Dias, M.S., Modesto, M., Ensinas, A., Nebra, S.A., Maciel Filho, R., Rossell, C.E.V. Improving bioethanol production from sugarcane: evaluation of distillation, thermal integration and cogenerations systems. Energy, 36, 3691-3703 (2011). https://doi. org/10.1016/j.energy.2010.09.024

Halvorsen, I.J., Skogestad, S. Energy efficient distillation. Journal of Natural Gas Science and Engineering, 3, 571-580 (2011). https://doi. org/10.1016/j.jngse.2011.06.002

Jana, A.K. Performance analysis of a heat integrated column with heat pumping. Separation and Purification Technology, 209, 18-25 (2019). https:// doi.org/10.1016/j.seppur.2018.07.011

Kimmel, E.J. Characteristics of a falling film distillation column. Ph.D. Thesis, University of Lousville, 1947.

Li, H., Wu, Y., Xingang, L., Gao, X. State-of-the-Art of Advanced Distillation Technologies in China. Chemical Engineering Technology, 39, 815-833, 2016. https://doi.org/10.1002/ceat.201500656

Lee, M., Long, N.V.D. Review of Retrofitting Distillation Columns Using Thermally Coupled Distillation Sequences and Dividing Wall Columns to Improve Energy Efficience. Journal of Chemical Engineering of Japan, 47, 87-108 (2014). https:// doi.org/10.1252/jcej.13we067

Luyben, W.L. Feed-stage multiplicity in multicomponent distillation. Industrial and Engineering Chemistry Research, 49, 3980-3982 (2010). https://doi.org/10.1021/ie1001108

Marangoni, C., Peruzzo, T., Parisotto, I.A.B., Ricardo, V.W., Claumann, C.A., Milanez, K.W., Mantelli, M.B.H., Quadri, M.B., Bolzan, A., Santos, M.C. dos, Medina, L.C., Machado, R.A.F. Falling film distillation column with heat transfer by means of a vapor chamber. Part II: operation with a temperature profile. Chemical Engineering Communications, 206, 1006-1014 (2019). https://doi.org/10.1080/00 986445.2018.1542255 
Marangoni, C., Meneguelo, A.P., Teleken, J.G., Werle, L.O., Milanez, K.W., Mantelli, M.B.H., Quadri, M.B., Bolzan, A., Santos, M.C. dos, Medina, L., Machado, R.A.F. Falling film distillation column with heat transfer by means of a vapor chamber Part I: Isotermal operation. Chemical Engineering Communications 206, 994-1005 (2019). https:// doi.org/10.1080/00986445.2018.1542250

Michels, V., Milanez, F., Mantelli, M. Vapor chamber heat sink with hollow fins. Journal of the Brazilian Society of Mechanical Sciences and Engineering, 34, 233-237 (2012). https://doi.org/10.1590/S167858782012000300002

Olujić, Ž., Jödecke, M., Shilkin, A., Schuch, G., Kaibel, B. Equipment improvement trends in distillation. Chemical Engineering and Processing: Process Intensification, 48, 1089-1104 (2009). https://doi. org/10.1016/j.cep.2009.03.004

Resetarits, M., Rebeau, T., Thurber, T. Column Revamps: From Outside to Inside. Chemical Engineering, 38-47 (2015).

Saifutdinov, A.F., Beketov, O.E., Ladoushkin, V.S., Nesterov, G.A. Distillation technology for the $21^{\text {st }}$ century. Hydrocarbon Asia, 40-43 (2002).

Saxena, N., Mali, N., Satpute, S. Study of thermally coupled distillation systems for energy-efficient distillation. Sadhana, 42, 119-128 (2017).
Silva Filho, V.F. da, Alves, J.L.F., Reus, G.F., Machado, R.A.F., Marangoni, C., Bolzan, A. Experimental evaluation of the separation of aromatic compounds using falling film distillation on a pilot scale. Chemical Engineering \& Processing: Process Intensification, 130, 296-308 (2018). https://doi. org/10.1016/j.cep.2018.06.026

Suleiman, B., Olawale, A.S., Waziri, S.M., Exergetic and economic assessment of distillation hybrid configurations for bioethanol refining. International Journal of Thermodynamics, 17, 221-231 (2014). https://doi.org/10.5541/ijot.537

Rong, B.G., Errico, M. Synthesis of intensified simple column configurations for multicomponent distillations. Chemical Engineering and Processing: Process Intensification, 62, 1-17 (2012). https://doi. org/10.1016/j.cep.2012.10.005

Shenvi, A.A., Shah, V.H., Agrawal, R. New multicomponent distillation configurations with simultaneous heat and mass integration. AIChE Journal, 59, 272-282 (2013). https://doi. org/10.1002/aic.13971

Wang, F., Luo, Y., Yuan, X. A formulation methodology for multicomponent distillation sequences based on stochastic optimization. Chinese Journal of Chemical Engineering, 24, 1229-1235 (2016). https://doi.org/10.1016/j.cjche.2016.04.046 
